\title{
Anterior ischaemic optic neuropathy associated with central retinal vein occlusion
}

\begin{abstract}
Purpose To report the unusual association between non-arteritic anterior ischaemic optic neuropathy (NAION) and non-ischaemic central retinal vein occlusion (CRVO) in two patients.

Methods Case reports are presented.

Results Non-ischaemic CRVO was manifested by dilated, tortuous retinal veins with flameshape retinal haemorrhages. Fluorescein angiography showed prolonged arteriovenous transit time and normal retinal capillary perfusion without macular oedema. The presence of colour vision abnormalities, relative afferent pupillary defects, pale disc swelling and visual field deficits indicated that the visual loss was attributable entirely to NAION. Laboratory investigations disclosed impaired fibrinolytic function in case 1 and the presence of antiphospholipid antibodies in case 2.

Conclusions Compression of the central retinal vein by the swollen optic nerve could have predisposed to CRVO. The presence of thrombophilic abnormalities may have contributed to the concomitant occlusion of posterior ciliary arteries and central retinal vein. Ischaemic optic neuropathy needs to be considered in patients with CRVO when the visual acuity is not consistent with the retinal pathology.
\end{abstract}

Key words Antiphospholipid antibodies, Fibrinolysis, Ischaemic optic neuropathy, Prothrombotic disorders, Retinal vein occlusion

Ischaemic optic neuropathy occurs in two forms: arteritic, generally due to giant cell arteritis and occurring in the elderly, and nonarteritic occurring in a younger age group. The pathogenesis of non-arteritic anterior ischaemic optic neuropathy (NAION) is multifactorial, including structural and blood flow abnormalities resulting in vascular insufficiency in branches of the short posterior ciliary vessels supplying the retrolaminar optic nerve. ${ }^{1}$ In a typical attack of ischaemic optic neuropathy there is painless, fairly sudden visual loss
AHMED M. ABU EL-ASRAR, SABA A. AL RASHAED, ABDEL GALIL M. ABDEL GADER associated with an afferent pupillary defect, diminished colour perception, pale or hyperaemic disc swelling with or without flame-shaped haemorrhages present at or near the disc margin, and arcuate or altitudinal field defects. $^{2}$

This report describes two patients who presented with ischaemic optic neuropathy and a funduscopic appearance resembling nonischaemic central retinal vein occlusion (CRVO). To the best of our knowledge, such an association has not previously been reported; however, Gass ${ }^{3}$ stated that he has seen retinal venous obstruction in patients with ischaemic optic neuropathy.

\section{Case reports}

Case 1

A 50-year-old man presented with a 1 week history of decreased vision in the left eye. Past medical history was unremarkable. Best corrected visual acuity was $20 / 20$ in the right eye and counting fingers at 4 feet $(1.2 \mathrm{~m})$ in the left eye. Colour vision testing using Ishihara colour plates revealed 15 of 15 plates correctly identified with the right eye and 0 of 15 with the left eye. There was a $3+$ relative afferent pupillary defect in the left eye. The right fundus appeared normal. Ophthalmoscopy of the left eye revealed a markedly swollen optic disc that was covered by peripapillary and perivenous flame-shaped haemorrhages. In addition, the retinal veins were dilated and tortuous throughout the retina and no macular oedema was visible (Fig. 1). Visual field testing of the left eye with a Goldmann perimeter revealed a markedly constricted visual field. Fluorescein angiography showed a prolonged arteriovenous transit time ( $20 \mathrm{~s}$; normal $\leqslant 11 \mathrm{~s}$ ). There was no evidence of capillary non-perfusion or macular oedema.

Complete blood count, Westergren erythrocyte sedimentation rate, haematocrit, blood glucose, kidney and liver function tests, lipid profile, antinuclear antibody titres, antidouble-stranded DNA antibodies, C3 and C4 components of complement, serum protein electrophoresis and immunoelectrophoresis and 


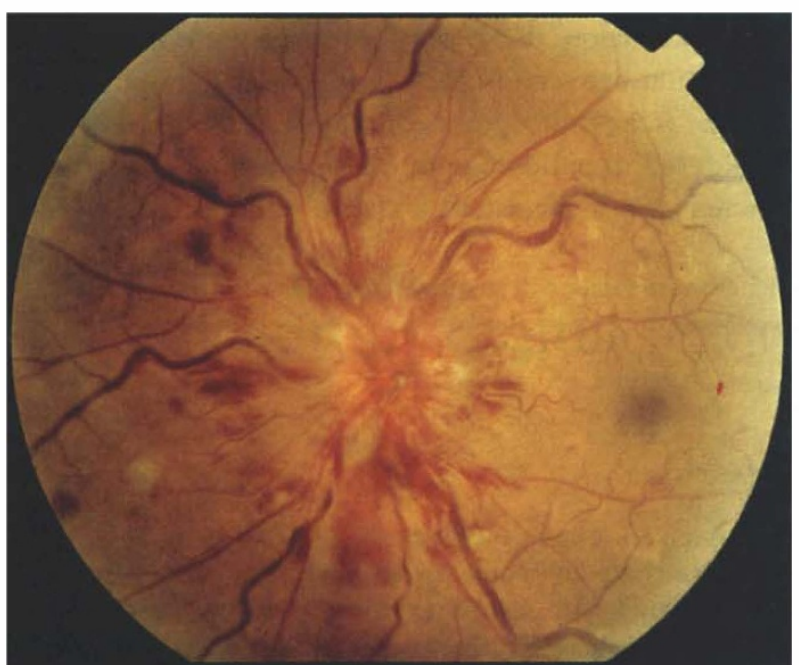

(a)

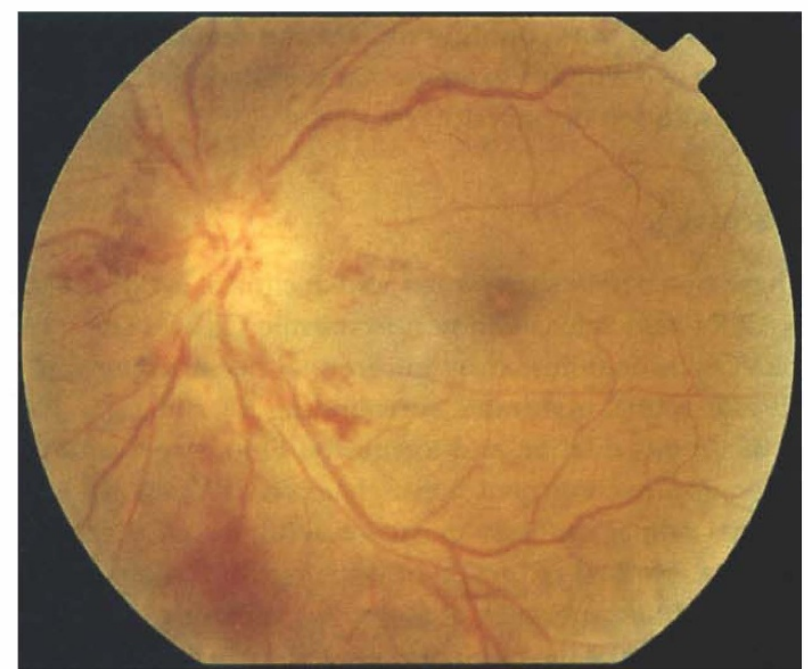

(b)

Fig. 1. Case 1. (a) Fundus photograph of the left eye. Notice the prominent optic disc oedema, retinal venous dilation and tortuosity, and flameshaped retinal haemorrhages. (b) Fifteen days later. Notice resolution of prepapillary haemorrhages showing diffuse pale optic disc swelling.

haemoglobin electrophoresis revealed normal findings. The patient was also investigated for the presence of antiphospholipid antibodies (anticardiolipin antibodies, the lupus anticoagulant and the antibodies responsible for the false positive serological test for syphilis 'Venereal Disease Research Laboratory Test') with negative results. Plasma fibrinogen, antithrombin III, protein C and protein $\mathrm{S}$ activities and factor XII clotting activity yielded normal results. Euglobulin clot lysis time (a measure of overall fibrinolytic activity) was prolonged (more than $5 \mathrm{~h}$; normal $<3 \mathrm{~h}$ ) indicating depressed overall fibrinolytic activity. Tissue plasminogen activator activity was $12.8 \mathrm{ng} / \mathrm{ml}$ (normal 1-12 ng/ml), and plasminogen activator inhibitor activity was markedly elevated at $70 \mathrm{ng} / \mathrm{ml}$ (normal $4-43 \mathrm{ng} / \mathrm{ml}$ ). Stimulated fibrinolysis after a venous occlusion test still gave a euglobulin clot lysis time of more than $5 \mathrm{~h}$, indicating a poor fibrinolytic response.

On follow-up examination 15 days later the prepapillary haemorrhages had cleared, revealing diffuse pale optic disc swelling, and the diagnosis of anterior ischaemic optic neuropathy was made (Fig. 1). Aspirin, $100 \mathrm{mg}$ daily, was begun. Two months later, the patient's visual acuity remained unchanged and funduscopic examination showed resolution of retinal haemorrhages and optic atrophy.

\section{Case 2}

A 38-year-old woman noticed visual loss in her left eye associated with loss of colour vision for 10 days. Past medical history was remarkable as she was suffering from both insulin-dependent diabetes mellitus and hypertension. There was also a history of recurrent abortions. Best corrected visual acuity was 20/30 in the right eye and counting fingers at 3 feet $(1 \mathrm{~m})$ in the left eye. She correctly identified 15 of 15 Ishihara colour plates with the right eye and could not discern any colour test plates using the left eye. There was a $3+$ relative afferent pupillary defect in the left eye. Fundus examination of the right eye revealed a small crowded optic disc with no evidence of diabetic retinopathy. Ophthalmoscopy of the left eye showed diffuse pale optic disc swelling, with prominent peripapillary and perivenous flame-shaped haemorrhages. The retinal veins were dilated and tortuous and no macular oedema was visible (Fig. 2). Visual field testing of the left eye with a Goldmann perimeter revealed a markedly constricted visual field. Fluorescein angiography showed a prolonged arteriovenous transit time (18 s) with no evidence of capillary non-perfusion or macular oedema. A diagnosis of anterior ischaemic optic neuropathy with secondary non-ischaemic CRVO was made.

Laboratory studies similar to those undertaken in case 1 revealed the presence of antiphospholipid antibodies. IgM anticardiolipin antibodies were $40 \mathrm{mpl}$ units (normal 6-12 mpl units). The patient was admitted to hospital for intravenous methylprednisolone, $250 \mathrm{mg}$ every $6 \mathrm{~h}$ for 3 days. Oral corticosteroids were instituted and tapered over the next 4 weeks. Two months later, the

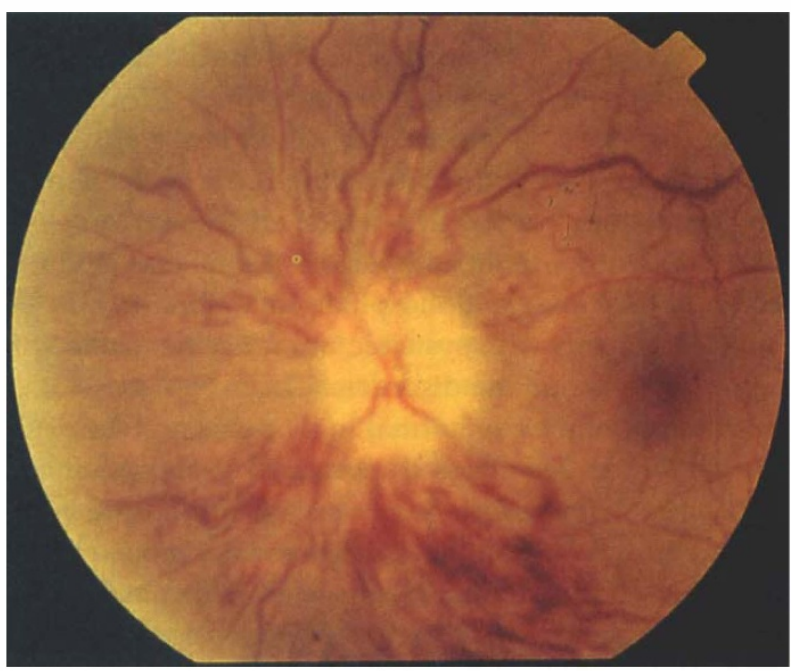

Fig. 2. Case 2. Fundus photograph of the left eye, showing diffuse pale optic disc swelling, dilation and tortuosity of the retinal veins, and flame-shaped retinal haemorrhages. 
visual acuity was counting fingers at 6 feet $(2 \mathrm{~m})$ in the affected eye. Fundus examination revealed optic atrophy and resolution of retinal haemorrhages.

\section{Discussion}

These two patients presented with a clinical syndrome of NAION associated with non-ischaemic CRVO. The CRVO was manifested by intraretinal haemorrhages in all four retinal quadrants surrounding the optic disc, with venous dilation and tortuosity. Fluorescein fundus angiography confirmed non-ischaemic CRVO with normal retinal capillary perfusion without macular oedema. Marked reduction of visual acuity, colour vision abnormalities, presence of a relative afferent pupillary defect, pallor of the optic disc, and visual field loss were consistent with the diagnosis of associated ischaemic optic neuropathy.

A variety of conditions affecting the optic nerve give rise to retinal vein occlusion as a secondary phenomenon. These include drusen of the optic disc, ${ }^{4,5}$ optic neuritis, ${ }^{6,7}$ optic nerve glioma ${ }^{8}$ and pseudotumour cerebri. ${ }^{9}$ It was speculated that $\mathrm{CRVO}$ associated with pseudotumour cerebri is due to increased intracranial pressure which directly compresses the optic nerve and vessels through the intravaginal optic nerve space that communicates with the subarachnoid space. ${ }^{10} \mathrm{CRVO}$ associated with drusen of the optic disc, ${ }^{4,5}$ optic neuritis ${ }^{6,7}$ and optic nerve glioma ${ }^{8}$ is hypothesised to be due to mechanical obstruction leading to secondary CRVO. Similarly, compression by the swollen optic nerve could have predisposed to retinal venous occlusion in our cases.

The two patients reported here had an associated thrombophilic (prothrombotic) state which may have contributed to the concomitant occlusion of the posterior ciliary arteries and central retinal vein giving rise to NAION and CRVO. Patient 1 had impaired fibrinolytic activity due to elevation of the plasma plasminogen activator inhibitor activity. The euglobulin clot lysis time, which is a measure of overall plasma fibrinolytic activity, was prolonged and the fibrinolytic response to the venous occlusion test was also poor. Reduced fibrinolytic activity has been reported before in $\mathrm{NAION}^{11}$ and retinal vein occlusion. ${ }^{12,13}$ Patient 2 had raised levels of IgM anticardiolipin antibodies indicating the involvement of antiphospholipid antibodies, which are known to be associated with arterial and venous thrombosis, and recurrent fetal loss. Antiphospholipid antibodies may be found in patients with systemic lupus erythematosus, and other autoimmune disorders. They are also described in otherwise normal individuals and this association has been termed 'primary antiphospholipid syndrome'. ${ }^{14}$ The association between antiphospholipid antibodies and $\mathrm{NAION}^{11,15,16}$ and retinal venous occlusion ${ }^{17,18}$ was previously reported. This patient had in addition diabetes mellitus and hypertension which are risk factors for small vessel occlusive disease.
In conclusion, this report describes the unusual association between NAION and CRVO. Non-arteritic anterior ischaemic optic neuropathy needs to be considered in patients with CRVO when the visual function is not consistent with the retinal findings.

The authors thank Ms Janette H. Cayetano for her secretarial assistance.

\section{References}

1. Hayreh SS. Anterior ischemic optic neuropathy. I. Terminology and pathogenesis. Br J Ophthalmol 1974;58:955-63.

2. Miller NR. Anterior ischemic optic neuropathy. In: Miller NR, editor. Walsh and Hoyt's clinical neuro-ophthalmology. Baltimore: Williams \& Wilkins, 1982:212-26.

3. Gass JDM. Stereoscopic atlas of macular diseases: diagnosis and treatment, 3rd ed. St Louis: CV Mosby, 1987:426.

4. Chern S, Magargal LE, Annesley WH. Central retinal vein occlusion associated with drusen of the optic disc. Ann Ophthalmol 1991;23:66-9.

5. ten Doesschate MJL, Manschot WA. Optic disc drusen and central vein occlusion. Doc Ophthalmol 1985;59:27-31.

6. Duker JJ, Sergott RC, Savino PJ, Bosley TM. Optic neuritis with secondary retinal venous stasis. Ophthalmology 1989;96:475-80.

7. Winterkorn JMS, Odel JG, Behrens MM, Hilal S. Large optic nerve with central retinal artery and vein occlusions from optic neuritis/perineuritis rather than tumor. J NeuroOphthalmol 1994;14:157-9.

8. Hovland KR, Ellis PP. Hemorrhagic glaucoma with optic nerve glioma. Arch Ophthalmol 1966;75:806-9.

9. Chern S, Magargal LE, Barv SS. Bilateral central retinal vein occlusion as an initial manifestation of pseudotumour cerebri. Ann Ophthalmol 1991;23:54-7.

10. Rios-Montenegro EN, Anderson DR, David NJ. Intracranial pressure and ocular hemodynamics. Ophthalmology 1973;89:53-8.

11. Acheson JF, Saunders MD. Coagulation abnormalities in ischemic optic neuropathy. Eye 1994;8:89-92.

12. Abu El-Asrar AM, Abdel Gader AGM, Al-Amro S, AlMomen AK. Fibrinolytic activity in retinal vein occlusion. Int Ophthalmol 1998;21:343-8.

13. Pedruzzi M, De Rosa V, Fonda S, Coccheri S. Haemostatic studies in retinal vein occlusion: fibrinolytic response to venostasis as a prognostic factor from spontaneous recanalization. Thromb Res 1981;24:105-18.

14. Bick RL, Baker WF. Antiphospholipid and thrombosis syndromes. Semin Thromb Hemost 1994;20:3-15.

15. Levine SR, Crofts JW, Lesser GR, Floberg J, Welch KMA. Visual symptoms associated with the presence of a lupus anticoagulant. Ophthalmology 1988;95:686-92.

16. Galetta SL, Plock GL, Kushner MJ, Wyszynski RE, Brucker AJ. Ocular thrombosis associated with antiphospholipid antibodies. Ann Ophthalmol 1991;23:207-12.

17. Abu El-Asrar AM, Abdel Gader AGM, Al-Amro S, AlMomen AK. Hypercoagulable states in patients with retinal venous occlusion. Doc Ophthalmol 1998;95:133-43.

18. Coniglio M, Platania A, Di Nucci GD, Arcieri P, Modzrewska R, Mariani G. Antiphospholipid-protein antibodies are not an uncommon feature in retinal venous occlusions. Thromb Res 1996;83:183-8. 